\title{
Podcast on the Management of Adverse Events Associated with Lorlatinib
}

\author{
Todd M. Bauer · Erin M. Bertino
}

Received: September 28, 2021 / Accepted: January 17, 2022 / Published online: February 11, 2022

(C) The Author(s) 2022

Keywords: Adverse events; Lorlatinib; Lung cancer; Oncology; Podcast

\section{PODCAST TRANSCRIPT}

Todd Bauer (TB).

Erin Bertino (EB).

This podcast was supported by Pfizer Inc., with editorial support provided by Annette Smith of CMC Affinity, McCann Health Medical Communications, funded by Pfizer.

TB: Hi, my name's Todd Bauer. I'm a Senior Investigator at Sarah Cannon Research Institute and a partner at Tennessee Oncology in

Digital Features This article is published with digital features, including the podcast audio, to facilitate understanding of the article. To view digital features for this article go to https://doi.org/10.6084/m9.figshare. 18414407.

Supplementary Information The online version contains supplementary material available at https:// doi.org/10.1007/s12325-022-02050-3.

T. M. Bauer ( $\varangle)$

Sarah Cannon Cancer Research Institute and

Tennessee Oncology, PLLC, 250 25th Ave.,

Nashville, TN 37203, USA

e-mail: tbauer@tnonc.com

E. M. Bertino

The Ohio State University Comprehensive Cancer

Center, Columbus, OH, USA
Nashville. I appreciate the time to meet with you this morning, Erin, and I'm looking forward to this conversation we're going to have.

EB: Yes, I'm excited to chat this morning. My name is Erin Bertino, I'm an academic thoracic medical oncologist, and I work at the Ohio State University. This morning Todd and I are planning to go ahead and discuss the practical management of some of the adverse events we see associated with lorlatinib.

Our plan is to cover several topics, including some of the unmet needs in patients with anaplastic lymphoma kinase (ALK)-positive lung cancer, the development of lorlatinib, and how we're using it in clinical practice, as well as looking at how we manage some of the common adverse events, particularly central nervous system (CNS) toxicity and hyperlipidemia, that we see a lot in the clinic and are really of interest to clinicians.

Todd, do you want to give us some background on what you see as the unmet needs in patients with $A L K$-positive lung cancer and how lorlatinib fits in that landscape?

TB: Yes, that's a great question, and I think that it helps to go back and look a bit further back at the history of treating $A L K$-positive lung cancer, to really understand why there could be possibly an unmet need with so many drugs on the market.

We know that first-generation ALK tyrosine kinase inhibitor (TKI) crizotinib did show efficacy and benefit versus chemotherapy as a first- 
line treatment [1]; unfortunately, most patients did relapse and had acquired resistance to that drug [2]. We know that with $A L K$-positive disease, CNS progression is a big risk [3], with [about] 30-40\% of patients presenting with CNS metastases at the time of presentation [4-7], and knowing that over half of them will develop CNS metastases if treated with chemotherapy alone; so we need to find something that works better in the brain.

The second-generation TKIs that have been approved in the first line, alectinib and brigatinib $[8,9]$, showed efficacy benefits over crizotinib alone $[5,6,10,11]$, but still there's that risk of resistance to those drugs, where you develop a resistance mutation, specifically the G1202R resistance mutation [12].

Lorlatinib as a third-generation drug is a little bit different because the basic science of it is different, it's a macrocyclic molecule rather than a linear molecule, and it was really designed rationally to try and penetrate the blood-brain barrier more effectively [13, 14]. That is why it was designed, and it did get approval in second- or third-line after progressing on at least one prior second-generation ALK TKI, after it showed ability to salvage patients who had been treated with these other drugs $[15,16]$.

But the CROWN study, which was the lorlatinib first-line study, was published just over a year ago, and that again showed good benefit over crizotinib in the first-line setting and earned lorlatinib a first-line approval, similar to alectinib and brigatinib [7, 17].

That's sort of a fly through the history of treating $A L K$-positive lung cancer, based on the drugs we have available, but now comes the hard part: we have all these different weapons: which ones do we choose? And Erin, how do you know what you're going to use first, second or third when it comes to using all these drugs?

EB: It's not a straightforward question. In our clinical experience I see a fair number of $A L K$ patients, and that's always the first debate, now that we have multiple effective first-line ALK TKIs: when are we going to use lorlatinib versus when are we going to use alectinib or brigatinib? Trying to figure out which patients benefit is, I would say, one of our most common clinical challenges in the ALK space.

When I look at the data for the three different drugs, lorlatinib versus alectinib or brigatinib, I think there are a couple of things that stand out. One of the big ones is, like you mentioned earlier, we see a lot of brain metastases in our $A L K$-positive population, and one of the big failures of crizotinib was that patients were progressing in the CNS [18]. What we really saw that stood out to me in the CROWN trial was this improved CNS efficacy, or CNS progression-free survival, in patients with baseline brain metastases with lorlatinib, so I feel like that becomes an important consideration [7]. If a patient has brain metastases, particularly multiple brain metastases or ones where you want to maybe avoid other therapies like radiation, then I think looking at lorlatinib first makes sense, because we saw significantly better outcomes for those patients.

I think the other debate is, which is the best drug? When I've talked with other oncologists about this, and should we use the best-which people typically define as the most effectivedrug first, or should we save that drug, because in the case of lorlatinib we know that it's effective in two different settings: so CROWN shows us it's effective in the first-line setting [7], we also know, based on the original approval, that it's one of the only drugs that's effective after other TKIs, including some of the other second-generation TKIs $[15,16]$. So historically we start to think about that as it's hard to parse out which is the best drug. We've classically looked at survival, and all of the trials with alectinib, brigatinib and lorlatinib used progression-free survival as their primary endpoint [5-7], so one of the ongoing debates is, should we use the drug with the best progression-free survival, like we think about in other lung cancer settings $[19,20]$ ? The other question that I think is still developing is, what about overall survival? How is that going to be affected by your sequencing or by which drug you use first; and that's still a bit of an open question.

And then obviously the other big thing, we're treating real patients, so we want to know what sort of side effects are these patients going to experience, and how do we manage them? 
Todd, what has been your experience with using lorlatinib and managing these adverse events?

TB: Well, I've had the chance to use lorlatinib for a long time; I got to take part in the first-in-human dosing of this drug, so I've had patients on it for over $71 / 2$ years at this point. What we see when we look at the CROWN data specifically in that first-line population, half of the patients, or $49 \%$, on lorlatinib did have to be dose modified [49\% had AEs leading to dose interruption and $21 \%$ had AEs leading to dose reduction], but after dose modification only $7 \%$ of patients had to come off lorlatinib because of toxicity [7], so it may take a little bit more effort on our part to manage that, but it is manageable [21-23].

The side effects that we see with it [lorlatinib] are a little bit different than what we see with the other TKIs. Those common side effects we see with lorlatinib are hypercholesterolemia and hypertriglyceridemia [7]. There is also some edema.

But what is probably the most talked about are these CNS side effects that really grew out of the Phase I/II study when we were doing patients who'd had multiple prior TKIs and some of them multiple prior brain radiations as well $[15,16]$. There are a lot of questions about how we manage this and what these CNS side effects look like. Commonly they are presented as change in speech pattern, with almost a slowed speech pattern, like think about playing a record at 75\%; it's not word-finding difficulty so much as the speech is slow. There were some cognitive changes, some fuzziness of thinking, which I think we typically would consider to be 'chemo-brain' if this were a chemo, and then there were some psychotic events [e.g., hallucinations] that happened with this drug [17]. They were pretty dramatic, but with all of these, the important thing to remember is that almost all of them do resolve, some without even modifying the dose, some with dose hold and some with dose reduction $[17,24]$. Those are the things we think about, and I tend to be reassured that if we do see these side effects develop, a simple dose reduction is usually enough to manage it. The standard dosing for lorlatinib is $100 \mathrm{mg}$ once a day, and the first reduction is down to $75 \mathrm{mg}$ once a day, and the second reduction is down to $50 \mathrm{mg}$ once a day [17].

That usually makes us as oncologists nervous about, am I giving up efficacy if I'm dropping the dose by half? We have seen [25] and I have both the pharmacokinetic data and the patient data to say that no, we still get great efficacy of this drug, even if it's $50 \mathrm{mg}$ a day. In fact, I had one patient on it for $3 \frac{1}{2}$ years at just $50 \mathrm{mg}$ after he required a second dose reduction, and he has maintained a near complete response despite that reduction. So, we can manage these [side effects] quite well.

Have you seen any of these cognitive effects in any of your patients, Erin?

EB: I have seen a little bit, not as much as I maybe would have expected. I found that I was noticing it more in some of my patients who had the early access to lorlatinib. Much like your clinical experience, we did have trials available, particularly in the second-line and beyond, for lorlatinib before it was FDA approved, and so I had a few patients. One who comes to mind was a woman who had been heavily pre-treated and had brain metastasis at the time that she went onto lorlatinib. We noticed some kind of general cognitive slowing; her husband, who didn't always come with her to appointments, reported that she was getting a little bit confused at home. It sort of reminded me of late effects of patients who have had whole brain radiation, so my thought about it was, we know this patient has brain disease, and now they have a drug that's actively in the brain, and that seems to be triggering some of the side effects.

I've not been seeing as much of it in patients who were de novo, new diagnoses, without baseline brain metastases. I think that also raises a challenge for us as medical oncologists, as when patients start developing maybe not headaches but confusion or speech change, maybe not so much mood either, are these brain metastases or are these drug effects? My experience has been that this drug is so effective at controlling CNS disease that I think it's still on the differential, but it tends to be lower for me to think that they have failed lorlatinib and they are progressing in the brain than that 
lorlatinib is causing these side effects because it's in the brain, treating and/or preventing brain metastases. I think we still have to have a suspicion for brain metastases. I think as medical oncologists we tend to have a fairly low threshold to get brain imaging, but I think we also have to realize that sometimes a dose interruption, and, if there is not improvement with dose interruption or if there are recurrent symptoms after re-challenge, then dose reduction of lorlatinib is typically enough to take care of these side effects, like Todd mentioned. My experience has been similar; that if we do need to make modifications, patients tend to tolerate it well.

You mentioned, Todd, that you've seen some of the speech changes. Have you seen any of the mood changes or psychosis in your patient population?

TB: No, I have not seen much depression with it; the slowed speech is probably the most obvious thing. It's hard, though, for us as oncologists to pick up on some of those things, especially practicing in Nashville, where some patients just tend to have a slower speech pattern than [in] the South. How do I tell if somebody is a little bit depressed or not, in a 15-20-min visit once a month? I don't know about you, but I really try and get the caregivers involved early on, to make them aware to look for these things. Do you do that as well?

EB: Yes, I think that's absolutely a great point, talking to both the patient and the caregiver in the beginning of treatment. They've lived with these people, so they know what to watch for as possible side effects. I like to also make them aware that if they start to notice side effects, that they need to let us know. I've found sometimes patients or caregivers tend to feel like this is going to be the drug they need, so sometimes there is some hesitancy to talk to us about side effects they're noticing, particularly if it's things like mood changes.

I think the other piece is letting them know that it happens; if it happens, we can make modifications; that the drug stays effective, but we can help them feel more like themselves. Like anything we do in oncology, education is key. We know it's not experienced by all patients, but the patients who do have these adverse events, it's definitely well within our wheelhouse to manage these with dose modifications, like we do for the other side effects we see with the other TKIs.

Shifting gears a little bit, the other really common side effect that I feel like as oncologists we sort of stopped thinking about when we left internal medicine is this issue of the hyperlipidemia. Hypercholesterolemia and hypertriglyceridemia [are] happening typically early in the course of treatment [21], so unlike the CNS effects I feel like this is more of a lab abnormality where patients aren't noticing or feeling anything different, but we did see that most patients developed the side effects within the first couple of weeks [21]. Most of them were low grade but about $15 \%$ of patients [in the CROWN trial] had Grade 3 or 4 hypercholesterolemia and a little bit higher incidence of hypertriglyceridemia [7, 21].

How are you monitoring lipids and hyperlipidemia in your patients?

TB: I tend to start the conversation with the patient when we're talking about starting lorlatinib to just tell them to expect that we're going to have to start treatment for their cholesterol. I will certainly check it before we get started. I usually check it 2 weeks into treatment, a month into treatment and then monthly thereafter.

I think about this much like I think about managing hypothyroidism when patients are on an immune checkpoint inhibitor. I don't bat an eye any more seeing thyroid-stimulating hormone go from 4 to 0 to 25 in a month-long period. What I will do is start them on Synthroid and keep going, so this is the same thought process. We see that cholesterol starts to rise, and most of the patients who had severe elevations or Grade 3 or 4 elevations of their cholesterol are the patients who-and I had a couple of them-declined to start a statin; they thought they'd be able to exercise their way out of it or diet their way out of the hypercholesterolemia, and due to this mechanism, they can't, so they will need a statin.

I think that what we know is that the choice of that statin is pretty important, based on some cytochrome P450 (CYP450) interaction. Which 
ones do you use when you see this start to happen?

EB: Like you mentioned, I feel there are a couple of points there about the statin, so which statin is important. Lorlatinib actually has an interaction through CYP3A (CYP450 3A4) [26], so classically I would have gone to drugs like atorvastatin, because that's one I became familiar with as a resident, but the recommendation is actually pitavastatin, pravastatin or rosuvastatin, because they have the least interaction with the CYP450 enzymes, so have the least chance of drug-drug interaction with lorlatinib [21].

For triglycerides, that can be a little bit different, and they actually recommend, because of drug-drug interactions, fenofibrate, as being the preferred choice there [21]. I think the other important point is when you start the statin, and I think there's a school of thought, particularly if patients have baseline hyperlipidemia, to think about starting a statin at the same time we start lorlatinib versus, like you mentioned, [regular monitoring]—I've gone 50:50, so I have some patients where we talk about starting a statin up front or, if they're already on a statin, potentially switching statins. Then, there have been other patients where we will let them start the lorlatinib and then typically we will see that this hyperlipidemia starts to occur, and, if we didn't start a statin up front, we're usually starting a statin within the first month.

The other piece that makes it kind of unique, besides the fact it's just a lab-or maybe that is what makes it unique-it's primarily just a lab abnormality, and I think I've only had one patient where it got to a high enough grade that we actually had to hold the drug, but for the vast majority of patients they will run a somewhat high, Grade 1, Grade 2, hypercholesterolemia, have no symptoms and are able to continue the same dose.

Thinking about our experience with these drugs, if you had a friend who had just got diagnosed with an $A L K$-positive non-small cell lung cancer, what would you advise them to think about doing first line?

TB: That's pretty much the question we always get-if this were your mum or your dad or your brother, this is the 'please guide me like you care about me.' I'd like to think that that's how we always guide all of our patients; it just puts a bit more of a poignant tip on it when patients ask us that.

I think there is no question in my mind that if a patient presented with CNS metastases-my best friend from college called and said, hey, I've got this thing going on-if they had brain mets (metastases) present, they would start lorlatinib. There's no question that alectinib works well in the brain; it had like an $80 \%$ response rate in the brain in the ALEX study [6], and that's similar to the lorlatinib $80 \%$ response [7]. But the difference I think is when you look at that complete response in the brain, where it's 20 or $30 \%$ maybe [38\%] for alectinib [6], but it's $71 \%$ for lorlatinib [7], so clearly a differenceand again these are cross-trial comparisons, which we're never supposed to do, but we always do anyway. But it does seem to be more potent in the brain; so, if they had brain metastases present at diagnosis, I think lorlatinib is the right answer.

Then, we get to that other part. My best friend from college who's, let's say, early 40sI'd like to think we're still early 40s-who is a Certified Public Accountant and is terrified about the thought of having brain mets. Then, I would probably want to think about lorlatinib in that case as well; again at $2.8 \%$ CNS progression at 1 year was all we saw. The KaplanMeier curve for that is more like a straight line, not a curve at all [7].

If it's a 75-year-old who has it, and they're like 'yeah, I suffered from depression' or 'I don't want to have trouble with my speech,' maybe that's when you start to look at alectinib. Of course, the biggest question in my mind, that I don't know we're going to get a quick answer to, is how do we best give each and every patient the longest, good duration of benefit with good quality of life? None of these drugs are curative, so if I can stack drug $\mathrm{A}$, then $\mathrm{B}$, then $\mathrm{C}$ and get 10 years, does it matter if I get 7 years if I do drug $C$ first and then 2 more? We don't know those answers.

I use sports analogies a lot, and this question of 'do you use your best drug first?' to me is, do you keep Michael Jordan on the bench and bring him in in the second half if you're losing 
the game or do you put Michael Jordan in to start the game and just never get behind? I sort of think of lorlatinib as that: it's the most potent; it's the best shot; so where do you want to use that card, I guess.

EB: Yes, I think that's an excellent point, because I think the other clinical space where we're seeing it [this question of sequencing] now is patients who started generally the second-generation TKIs before the approval of lorlatinib first line, and so I think there is definitely still a role for using lorlatinib second line.

Like you mentioned, on a case-by-case basis I think you can sometimes make an argument that you want to try one of the other TKIs first, and use lorlatinib as salvage, because I think, as you mentioned, the unanswered question is, if we use lorlatinib as salvage are we going to ultimately have a better overall survival, or the opposite of that is, if we use lorlatinib first, what comes next?

Whether you are using it first line or second line, what are you usually doing as far as dosing? I know with some of the older drugs like afatinib, sometimes people were starting at a reduced dose, like starting at the 30 instead of the 40 because of toxicity. Are you doing any of that with lorlatinib?

TB: I tend to not, and my rationale for that is I feel very comfortable that if we see these adverse reactions and we're forced to lower the dose, we can. More is usually better in treating cancer, right? The more of the drug I can give, the better my chance of having good efficacy. My concern about starting it [lorlatinib] at a lower dose, if I start a patient at $75 \mathrm{mg}$ and she does great for 2 months and we see a 50\% reduction in her tumor, what incentive is there for me to raise that dose, to go to the recommended dose? I'm probably not going to do it, so what we don't know then is, if I have to drop it, I have to drop it and accept that there may be some fall-off in benefit.

I still know that $75 \mathrm{mg}$ is a good dose [for lorlatinib], but does $100 \mathrm{mg}$, by virtue of being more, does it last longer? Do we get a more rapid cell kill? We just don't know, so I hate to give up the chance for more efficacy for the concern of potential toxicity that hasn't proven itself to be there, especially when I know I can just reduce the dose and the toxicity usually goes away. How about you?

EB: I agree, I would say with all of the newer [ALK TKIs] -alectinib, brigatinib and lorlatinib, although we know brigatinib has a different dosing schedule [9]-I agree with you. I think we start, if we're going to start the lorlatinib we start at the full dose. I routinely do check-ins around 2 to 3 weeks after starting, and I wouldn't say I have a low threshold. I tend to start with dose interruption before dose reduction, knowing that we have something to step down. I agree with you-I think it sounds good in theory, but I think in practice it's actually challenging to dose escalate, because patients are usually comfortable at the dose they've started.

I've also found some patients are hesitant to dose reduce, so sometimes that's a different discussion where you have to counsel them about the fact that it makes sense to go ahead and dose reduce-it still works; everybody ends up at a different dose. I would say with almost all the TKIs, I've found over time, I start at the highest dose-most of my patients I feel like over time will ultimately end up on at least one dose reduction, but I like to get as much time at the full dose as we can.

TB: Yes.

EB: What about the efficacy? When we're starting to think about lorlatinib versus the other ALK TKIs, how do you think it stacks up when we start looking at the data for survival, and we've already talked a lot about toxicity?

TB: It's hard-again, here's this cross-trial comparison thing. We have three studies, and if you include the eXalt study with ensartinib, four studies, looking at a second- or third-generation ALK inhibitor against crizotinib. All of them are better than crizotinib, there's no question about that $[5-7,10,11,27]$. Then, you have to try and parse out, well, are they any different?

I think if you look at two pieces of data that came out of the first-line studies that may suggest that lorlatinib clinically is better, one is the hazard ratio for progression-free survival: for alectinib, brigatinib and ensartinib we see a hazard ratio of right at 0.5 . That's great, that is a wonderful reduction in risk of progression; the 
hazard ratio for lorlatinib was 0.28 for the blinded independent review [5-7, 27]. If [for lorlatinib] you look at the investigator-assessed [hazard ratio], it was 0.21 , which is even better, but in the blinded independent review, the primary outcome was a hazard ratio of 0.28 , and that median PFS was not yet reached at the first data cut at about 18 months, so it looks like the progression-free survival is certainly not going to be any worse than the second-generation ALK TKIs [7].

I think you go back and look again at that intracranial complete response rate: do I think there is a big difference in a $1-\mathrm{mm}$ residual whatever on MRI versus a complete response? Clinically, probably not, but if I can shrink something from 5 to $0 \mathrm{~mm}$, I'd much rather do that than $5 \mathrm{~mm}$ to $2 \mathrm{~mm}$ and call it partial response. I think that trying to look at those clinically is probably the best we're going to get for quite some time, is looking across these trials.

Now, let me ask you: if I blindfolded you and had three patients on three different drugs, not counting the pill burden or how many times a day they're taking it, just looking at toxicity, would you be able to tell these drugs apart?

EB: I think it would be challenging, to be honest, because there are some that are universal: so I feel the universal side effects are things like GI upsets, to some degree a mild hepatic toxicity, obviously we saw more of that with crizotinib than we do with the newer generation ALK inhibitors [5-7]. Then, [in] my clinical experience edema has been problematic for me, particularly in my older patients, across the TKI spectrum.

I think beyond that if they had hyperlipidemia I'd definitely think it was the lorlatinib. I do still like alectinib, because I feel it has, when we look at the trial data, a favorable toxicity profile. They did see slightly fewer dose reductions than we saw with the other TKIs, although I feel like that is neither here nor there, but ultimately the progression-free survival I think speaks more than that [5-7].

Brigatinib we know has some unique side effects; it's one of the ones I've used the least because of where it fell in getting approved, but that one we know has the special dose escalation because of this risk of early pneumonitis, so we've seen pneumonitis to some small degree across all of the TKIs, but they saw this unique pneumonitis side effect with the brigatinib, so I feel like it would be challenging $[5,8,9,17]$.

I think there are a couple where if it was a blinded trial I might think, well, if they had pneumonitis maybe it was brigatinib, or if they had hyperlipidemia I'd think it was lorlatinib. Otherwise, I feel they are all effective, all fairly similar, and all of them, including lorlatinib, really seem to be able to have a sustained dose that's effective. What have you thought?

TB: The hyperlipidemia is the dead giveaway if you're trying to guess which is which. I do think you probably would see more of the CNS side effects with lorlatinib, and that might stand out. I think this is a great problem to have, as we think about this $A L K$-positive treatment world: we're trying to decide between a drug [alectinib] that works in $80 \%$ of patients in the brain [6] and another drug [lorlatinib] that works at a complete response of $71 \%$ of patients in the brain, [and also] working in the other 10 to $12 \%$ [7].

There's not a wrong choice here. It's how do you sequence it and what's important to you about the side effects and toxicity, and it's what we're comfortable with as physicians. It's always easier to give a drug that I know is easy to give because I have to do less about it, and if this is a new drug for me to give, maybe I've heard these stories about depression and all that, and I'm just like, no way, don't need it, we've got alectinib, we'll go to that if we have to, but with just a little bit of dose reduction it is pretty obvious that we can manage this drug and the side effects pretty well. I think it's a wonderful place to be, to have all these options for our patients, not that we can't get better, but we're in a good place, with lots of options for our patients.

EB: I just echo that I agree that with a lot of good options, I think the key as we get newer drugs like lorlatinib approved in the first line is realizing that, like everything we do, there is toxicity, but it's nothing that we can't manage as medical oncologists, to keep moving the field forward. 
TB: Yes, absolutely. Well, Erin, I think we've touched on a lot of things during our talk this morning. This has been a fun first podcast of my life, so I hope you've enjoyed it. I think we've got to talk about a lot of good stuff, and I hope all those of you who are listening have found it useful, and we look forward to doing more of these.

\section{ACKNOWLEDGMENTS}

Funding. This podcast has been supported by Pfizer Inc. The Rapid Service Fee and Open Access publication were funded by Pfizer.

Editorial assistance. Editorial support was provided by Annette Smith, PhD, of CMC AFFINITY, McCann Health Medical Communications, and was funded by Pfizer Inc.

Authorship. All named authors meet the International Committee of Medical Journal Editors (ICMJE) criteria for authorship for this article, take responsibility for the integrity of the work as a whole, and have given their approval for this version to be published.

Disclosures. Todd M. Bauer: Dr. Bauer reports receiving grant support, paid to his institution, from Daiichi Sankyo, MedPacto, Incyte, Mirati Therapeutics, MedImmune, AbbVie, AstraZeneca, MabVax Therapeutics, Stemline Therapeutics, Merck, GlaxoSmithKline, Novartis, Genentech, Deciphera Pharmaceuticals, Merrimack Pharmaceuticals, ImmunoGen, Millennium Pharmaceuticals, Phosplatin Therapeutics, Calithera Biosciences, Kolltan Pharmaceuticals, Principia Biopharma, Peloton Therapeutics, Immunocore, Roche, Aileron Therapeutics, Amgen, Onyx Pharmaceuticals, Sanofi, Boehringer Ingelheim, Astellas Pharma, Five Prime Therapeutics, Jacobio Pharmaceuticals, TopAlliance Biosciences, Janssen Pharmaceutica, Clovis Oncology, Takeda, Karyopharm Therapeutics, and ARMO BioSciences; grant support, paid to his institution, consulting fees, fees for serving on a speakers bureau, and travel support from Eli Lilly and Bayer; grant support, paid to his institution, consulting fees, and travel support from Bristol Myers Squibb, Foundation Medicine, and Loxo Oncology; grant support and consulting fees, paid to his institution, from Leap Therapeutics; grant support and consulting fees, paid to his institution, and travel support from Ignyta and Moderna Therapeutics; grant support and consulting fees, paid to his institution, and consulting fees from Pfizer; consulting fees and travel support from Guardant Health; and consulting fees from Exelixis and Blueprint Medicines. Erin M. Bertino: Dr. Bertino reports clinical trial support (drug only) from Merck and Lilly and consulting fees from Bristol Myers Squibb, Pfizer, OncLive, and Dava Oncology.

Compliance with Ethics Guidelines. This article does not contain any studies with human participants or animals performed by any of the authors.

Open Access. This article is licensed under a Creative Commons Attribution-NonCommercial 4.0 International License, which permits any non-commercial use, sharing, adaptation, distribution and reproduction in any medium or format, as long as you give appropriate credit to the original author(s) and the source, provide a link to the Creative Commons licence, and indicate if changes were made. The images or other third party material in this article are included in the article's Creative Commons licence, unless indicated otherwise in a credit line to the material. If material is not included in the article's Creative Commons licence and your intended use is not permitted by statutory regulation or exceeds the permitted use, you will need to obtain permission directly from the copyright holder. To view a copy of this licence, visit http://creativecommons.org/licenses/by$\mathrm{nc} / 4.0 /$.

\section{REFERENCES}

1. Solomon BJ, Mok T, Kim D-W, et al. First-line crizotinib versus chemotherapy in $A L K$-positive lung cancer. N Engl J Med. 2014;371:2167-77. 
2. Katayama R, Shaw AT, Khan TM, et al. Mechanisms of acquired crizotinib resistance in ALK-rearranged lung Cancers. Sci Transl Med. 2012;4:120ra17.

3. Zhang I, Zaorsky NG, Palmer JD, Mehra R, Lu B. Targeting brain metastases in ALK-rearranged nonsmall-cell lung cancer. Lancet Oncol. 2015;16: e510-21.

4. Johung KL, Yeh N, Desai NB, et al. Extended Survival and Prognostic Factors for Patients With ALKRearranged Non-Small-Cell Lung Cancer and Brain Metastasis. J Clin Oncol. 2016;34:123-9.

5. Camidge DR, Kim HR, Ahn M-J, et al. Brigatinib versus crizotinib in $A L K$-positive non-small-cell lung cancer. N Engl J Med. 2018;379:2027-39.

6. Peters S, Camidge DR, Shaw AT, et al. Alectinib versus crizotinib in untreated $A L K$-positive nonsmall-cell lung cancer. N Engl J Med. 2017;377: 829-38.

7. Shaw AT, Bauer TM, de Marinis F, et al. First-Line Lorlatinib or Crizotinib in Advanced ALK-Positive Lung Cancer. N Engl J Med. 2020;383:2018-29.

8. Genentech USA Inc. ALCENSA ${ }^{\circledR}$ (alectinib): Prescribing Information. 2021. https://www.gene. com/download/pdf/alecensa_prescribing.pdf. Accessed 24 Jan 2022.

9. ARIAD Pharmaceuticals Inc. ALUNBRIG ${ }^{\circledR}$ (brigatinib): Prescribing Information. 2021. https://www. alunbrig.com/assets/pi.pdf. Accessed 24 Jan 2022.

10. Camidge DR, Dziadziuszko R, Peters S, et al. Updated efficacy and safety data and impact of the EML4$A L K$ fusion variant on the efficacy of alectinib in untreated $A L K$-positive advanced non-small cell lung cancer in the global Phase III ALEX Study. J Thorac Oncol. 2019;14:1233-43.

11. Camidge DR, Kim HR, Ahn MJ, et al. Brigatinib versus crizotinib in advanced ALK inhibitor-naive $A L K$-positive non-small cell lung cancer: second interim analysis of the Phase III ALTA-1L trial. J Clin Oncol. 2020;38:3592-603.

12. Gainor JF, Dardaei L, Yoda S, et al. Molecular Mechanisms of Resistance to First- and SecondGeneration ALK Inhibitors in ALK-Rearranged Lung Cancer. Cancer Discov. 2016;6:1118-33.

13. Johnson TW, Richardson PF, Bailey S, et al. Discovery of (10R)-7-amino-12-fluoro-2,10,16-trimethyl-15-oxo-10,15,16,17-tetrahydro- $2 \mathrm{H}-8,4$ (metheno)pyrazolo[4,3- $h][2,5,11]$-benzoxadiazacyclotetradecine-3-carbonitrile (PF-06463922), a macrocyclic inhibitor of anaplastic lymphoma kinase (ALK) and c-ros oncogene 1 (ROS1) with preclinical brain exposure and broad-spectrum potency against ALK-resistant mutations. J Med Chem. 2014;57:4720-44.

14. Zou HY, Friboulet L, Kodack DP, et al. PF-06463922, an ALK/ROS1 inhibitor, overcomes resistance to first and second generation ALK inhibitors in preclinical models. Cancer Cell. 2015;28:70-81.

15. Shaw AT, Felip E, Bauer TM, et al. Lorlatinib in nonsmall-cell lung cancer with $A L K$ or ROS1 rearrangement: an international, multicentre, open-label, single-arm first-in-man phase 1 trial. Lancet Oncol. 2017;18:1590-9.

16. Solomon BJ, Besse B, Bauer TM, et al. Lorlatinib in patients with $A L K$-positive non-small-cell lung cancer: results from a global phase 2 study. Lancet Oncol. 2018;19:1654-67.

17. Pfizer Inc. LORBRENA ${ }^{\circledR}$ (Iorlatinib): Prescribing Information. 2021. http://labeling.pfizer.com/ ShowLabeling.aspx?id=11140. Accessed 24 Jan 2022.

18. Toyokawa G, Seto T, Takenoyama M, Ichinose Y. Insights into brain metastasis in patients with $A L K+$ lung cancer: is the brain truly a sanctuary? Cancer Metastasis Rev. 2015;34:797-805.

19. Camidge DR. Lorlatinib should not be considered as the preferred first-line option in patients with advanced ALK rearranged NSCLC. J Thorac Oncol. 2021;16:528-31.

20. Nagasaka M, Ou SI. Lorlatinib should be considered as the preferred first-line option in patients with advanced $A L K$-rearranged NSCLC. J Thorac Oncol. 2021;16:532-6.

21. Bauer TM, Felip E, Solomon BJ, et al. Clinical management of adverse events associated with lorlatinib. Oncologist. 2019;24:1103-10.

22. Nagasaka M, Ge Y, Sukari A, Kukreja G, Ou SI. A user's guide to lorlatinib. Crit Rev Oncol Hematol. 2020;151:102969.

23. Reed M, Rosales AS, Chioda MD, Parker L, Devgan $\mathrm{G}$, Kettle J. Consensus recommendations for management and counseling of adverse events associated with lorlatinib: a guide for healthcare practitioners. Adv Ther. 2020;37:3019-30.

24. Solomon BJ, Mok TS, Hayashi H, et al. 1199P Dose modification for the management of CNS adverse events in the phase III CROWN study of lorlatinib in non-small cell lung cancer (NSCLC). Ann Oncol. 2021;32(suppl 5):S957-8.

25. Chen J, Ruiz-Garcia A, James LP, et al. Lorlatinib exposure-response analyses for safety and efficacy in aphase I/II trial to support benefit-risk 
assessment in non-small cell lung cancer. Clin Pharmacol Ther. 2021;110:1273-81.

26. Chen J, XuH, Pawlak S, et al. The effect of rifampin on the pharmacokinetics and safety of lorlatinib: results of a phase one, open-label, crossover study in healthy participants. Adv Ther. 2020;37:747-58.
27. Horn L, Wang Z, WuG, et al. Ensartinib vs crizotinib for patients with anaplastic lymphoma kinasepositive non-small cell lung cancer: a randomized clinical trial. JAMA Oncol. 2021;7:1617-25. 